\title{
Microwave-assisted synthesis of photochromic fulgides
}

\author{
SIVASANKARAN NITHYANANDAN, CHINNUSAMY SARAVANAN, \\ SENGODAN SENTHIL and PALANINATHAN KANNAN* \\ Department of Chemistry, Anna University, Chennai 600025 \\ e-mail: pakannan@annauniv.edu
}

MS received 27 January 2009; revised 10 August 2009; accepted 19 August 2009

\begin{abstract}
The oxazole and indole based heterocyclic photochromic fulgides were synthesized from their corresponding fulgenic acid derivatives by clay catalysed microwave irradiation methodology. Improved yields of fulgides were observed by the microwave irradiation method as compared other chemical methods employed so far. The proportions of clay (montmorillonite KSF) and isopropenyl acetate play a key role in increasing the yields of fulgides.
\end{abstract}

Keywords. Photochromism; fulgenic acid; fulgides; microwave-assisted synthesis; anhydride; cyclization.

\section{Introduction}

Microwave heating has taken as incontestable place in analytical and organic laboratories practice as a very effective and non-polluting method of activation. The organic reactions were carried out under solvent-free reaction conditions and microwave irradiation lead to large reductions in reaction times, enhancement in conversions, and sometime in selectivity with several advantages of environmental approach termed green chemistry. ${ }^{1,2}$ The design and development of highly sensitive and reliable methods for growth of molecular level device is of scientific interest, wherein the yield restrict and suppress the development of new concepts and a challenging task in confronting chemistry. Fulgide is one of the most promising organic photochromic candidates for optical device application. Fulgides undergo reversible photo-cyclization reaction between their two isomers at well-separated absorption maximum upon irradiation with appropriate wavelength of light. ${ }^{3}$ This unique property made these materials considered to utilize in optical switches and optical data storage devices. ${ }^{4}$ These devices should be capable of ultrafast parallel access of stored information, erasable, good thermal stability and good fatigue resistance with proficient in non-destructible read-out. ${ }^{5}$ The aromatic heterocyclic ring structures containing photochromic fulgides are excellent candidates; especially indolyl and oxazolyl fulgides have distin-

\footnotetext{
*For correspondence
}

guished photochromic properties attributed to their high thermal stability, strong fluorescence and enhanced fatigue resistance compared to other fulgides. $^{6-9}$ The research articles regarding fulgides mainly focused on their thermal irreversibility, photofatigue resistance and high efficiency in a rapid photoconversion processes. The fulgide synthesis involves Stobbe condensation of carbonyl compounds with isopropylidene diethyl succinate followed by cyclization of fulgenic acid using DCC and acetyl chloride does not provide high yield of desired product, particularly when the reactants are highly substituted. ${ }^{10}$ To increase the yield of fulgide, Thomas et al attempted to synthesize indole substituted fulgide through base catalysed ring-opening reaction of lactones followed by dehydration using acetyl chloride provide below $30 \%$ of yield. ${ }^{11}$ Lee et al recently prepared fulgimide from fulgides through microwave-assisted reaction with good yield at low reaction time. ${ }^{12}$ This work deals with hitherto unreported synthesis and characterization of oxazole and indole based heterocyclic photochromic fulgides through clay catalysed microwave irradiation method from their corresponding fulgenic acid. In addition, preparation of new vanillin containing oxazolyl fulgenic acid is discussed.

\section{Experimental}

\subsection{Reagents}

Diethylsuccinate, acetone, $t$-butyl alcohol, potassium tertiarybutoxide, sodium hydride, 4-methoxyaniline, 
sodium hydroxide, hydroquinone, and 1-bromobutane (Merck, Germany) were used as received. Methanol, ethanol, phenol, THF, diethyl ether, chloroform, triethylamine, dimethylformamide (DMF) (SRL, India) and other solvents were purified by the reported procedures. ${ }^{13}$

\subsection{Instrumentation}

The infrared spectra were obtained on a Bruker IFS $66 \mathrm{~V}$ Fourier transform spectrometer using $\mathrm{KBr}$ pellets. High-resolution ${ }^{1} \mathrm{H}$ and ${ }^{13} \mathrm{C}$-NMR spectra were recorded on a Bruker $300 \mathrm{MHz}$ spectrometer in $\mathrm{CDCl}_{3}$ with TMS as an internal standard. The absorption spectra of fulgides in spectroscopic grade chloroform solution were measured on a Shimadzu UV260 spectrophotometer. The photocolorationdecolaration reaction of fulgides was carried out using a 500-W high-pressure Hg lamp (Ushio SX-UI 5000) equipped with a cut filter (Sigma, UTVAF$35 \mathrm{U})$ for UV irradiation $(360 \mathrm{~nm})$ and with a cut filter (Sigma, DIF-GRE) for visible light $(560 \mathrm{~nm})$.

\subsection{Synthesis of 2-[1,3-dimethyl-2-indolyl- methylene]-3-isopropylidenesuccinic acid (IFA)}

The IFA was synthesized according to the reported procedure. ${ }^{10}$ A flask charged with $60 \%$ sodium hydride in paraffin oil $(0.06 \mathrm{~mol}, 3.45 \mathrm{~g})$ and washed with hexane to remove the oil completely, to this, benzene $(120 \mathrm{~mL})$ was added at room temperature and stirred. A solution of 1,3-dimethylindole-2-carboxyaldehyde $(0.04 \mathrm{~mol}, 7 \mathrm{~g})$ (1) and isopropylidenediethyl succinate (2) $(0.04 \mathrm{~mol}, 8.6 \mathrm{~g})$ in benzene $(50 \mathrm{~mL})$ were added drop-wise to the reaction mixture at ambient temperature. After $1 \mathrm{~mL}$ of above solution was added, ethanol ( 2 drops) was added to initiate the reaction, followed by addition of remaining solution in a period of $3 \mathrm{~h}$. After completion of addition, the reaction mixture was allowed to stir for another $16 \mathrm{~h}$. The reaction mixture was subsequently quenched with ethanol and poured into crushed ice. The organic layer was separated and extracted with $10 \%$ sodium hydroxide solution $(3 \times 150 \mathrm{~mL})$. All the aqueous layers were combined and acidified with dilute hydrochloric acid. Liberated product was extracted with ethyl acetate and dried over anhydrous sodium sulphate. Solvent was removed under vacuum to afford diacid, which was hydrolysed in potassium hydroxide ethanol solution under reflux condition for $6 \mathrm{~h}$. After completion of reaction, flask was cooled to room temperature; dipotassium salt was filtered and washed with excess of ethanol. Then salt was dissolved in water and acidified with dilute hydrochloric acid to afford crude diacid. The obtained diacid was filtered, washed with excess of water and dried. The crude product was further purified by column chromatography (silica gel, ethyl acetate and chloroform) to afford bright yellow coloured powder, which was used as such for subsequent reaction.

\subsection{Synthesis of 2-[1,3-dimethyl-2-indolyl- methylene]-3-isopropylidenesuccinic anhydride (IFO)}

The isopropenyl acetate $(6.6 \mathrm{~mL}, 60 \mathrm{mmol})$ was added into blended mixture of IFA $(1.57 \mathrm{~g}, 7.0 \mathrm{mmol})$ and montmorillonite KSF $(1 \mathrm{~g})$ in a flat-bottomed flask and stirred. It was irradiated under focused microwave $(2450 \mathrm{MHz})$ for $10 \mathrm{~min}$. After completion of reaction, mixture was cooled to room temperature and poured with excess of chloroform and stirred. After 30 min of stirring, the clay was filtered off and removed the chloroform under vacuum. The crude product was further purified by column chromatography to afford IFO as dark brown coloured powder $(1.23 \mathrm{~g}, 84 \%)$. M.p.: $123-125^{\circ} \mathrm{C}$. FT-IR (KBr, $\left.\mathrm{cm}^{-1}\right): 1852,1768(-\mathrm{C}=\mathrm{O}), 1635(-\mathrm{CH}=\mathrm{C}-), 1606$ $\left(-\mathrm{C}=\mathrm{C}\left(\mathrm{CH}_{3}\right)_{2}\right), 1371\left(\mathrm{~N}-\mathrm{CH}_{3}\right), 856$ (substituted aromatic). ${ }^{1} \mathrm{H}-\mathrm{NMR}\left(400 \mathrm{MHz}, \mathrm{CDCl}_{3}\right) \delta: 7.70(s, 1 \mathrm{H}$, (Ar-CH=C), $7.55(d, 1 \mathrm{H}, \mathrm{Ar}), 7.05-7.29(m, 3 \mathrm{H}$, Ar), $3.67\left(s, 3 \mathrm{H}, \mathrm{N}-\mathrm{CH}_{3}\right), 2.45\left(s, 3 \mathrm{H}, \mathrm{Ar}-\mathrm{CH}_{3}\right), 1.83$ $\left(s, 3 \mathrm{H},-\mathrm{C}=\mathrm{C}\left(\mathrm{CH}_{3}\right)_{2}\right), 1 \cdot 24\left(s, 3 \mathrm{H},-\mathrm{C}=\mathrm{C}\left(\mathrm{CH}_{3}\right)_{2} \cdot{ }^{13} \mathrm{C}-\right.$ $\operatorname{NMR}\left(400 \mathrm{MHz}, \mathrm{CDCl}_{3}\right) \delta: 165 \cdot 5,163.0$ (carbonyl), $159 \cdot 3(\mathrm{Ar}-\mathrm{CH}=\mathrm{C}), 139 \cdot 0,132 \cdot 2,128 \cdot 9,127 \cdot 4,125 \cdot 4$, $124 \cdot 7,120 \cdot 5,119 \cdot 9,117 \cdot 5,109 \cdot 4$ (aromatic), 30.85, 27.46, 25.9, 23.41, 11.02. Anal. Calcd. for $\mathrm{C}_{18} \mathrm{H}_{17} \mathrm{NO}_{3}$ : C, $73.26 \%, \mathrm{H}, 5.88 \%$, N, $4.75 \%$. Found C, $73.24 \%$, $\mathrm{H}, 5 \cdot 88 \%, \mathrm{~N}, 4 \cdot 70 \%$.

\subsection{Synthesis of 4-butyloxy-3-methoxybenzaldehyde}

A suspension of anhydrous $\mathrm{K}_{2} \mathrm{CO}_{3} \quad(36.29 \mathrm{~g}$, $0.268 \mathrm{~mol})$, pinch of $\mathrm{KI}$ and vanillin $(10 \mathrm{~g}, 0.066 \mathrm{~mol})$ in dry DMF $(260 \mathrm{~mL})$ were stirred at $90^{\circ} \mathrm{C}$ for $1 \mathrm{~h}$. 4-Bromobutane $(11.19 \mathrm{~mL}, 0.06 \mathrm{~mol})$ was added drop-wise to the reaction mixture and stirred additionally for $48 \mathrm{~h}$ at the same temperature. After completion of reaction, mixture was cooled to room temperature, poured into ice/water mixture and neu- 
tralized with $10 \%$ hydrochloric acid. The aqueous solution was extracted with diethyl ether $(3 \times$ $200 \mathrm{~mL}$ ) and combined organic layer washed with $10 \% \mathrm{KOH}$ solution $(3 \times 250 \mathrm{~mL})$, saturated brine solution $(3 \times 250 \mathrm{~mL})$ and dried over anhydrous sodium sulphate. Solvent was removed under vacuum to afford compound $\mathbf{3}$ as brown coloured oil $(7.5 \mathrm{~g}, 60 \%)$. FT-IR $\left(\mathrm{KBr}, \mathrm{cm}^{-1}\right): 2942$ and 2865 $\left(-\mathrm{CH}_{2}-\right), 1603$ and 1514 (aromatic $\left.\mathrm{C}-\mathrm{H}\right), 1681(\mathrm{Ar}-$ $\mathrm{C}=\mathrm{O}), 1164$ and $1084(\mathrm{C}-\mathrm{O}-\mathrm{C}) .{ }^{1} \mathrm{H}-\mathrm{NMR}(400 \mathrm{MHz}$, $\left.\mathrm{CDCl}_{3}\right) \delta: 9.67(s, 1 \mathrm{H},-\mathrm{CHO}), 7.21(s, 1 \mathrm{H}, \mathrm{Ar})$, 6.82-7.04 ( $m, 2 \mathrm{H}, \mathrm{Ar}), 3.72\left(s, 3 \mathrm{H}, \mathrm{Ar}-\mathrm{O}-\mathrm{CH}_{3}\right)$, $3.56\left(t, 2 \mathrm{H}, \mathrm{Ar}-\mathrm{O}-\mathrm{CH}_{2}-\right), 0.82-1.52\left(m, 7 \mathrm{H},-\mathrm{CH}_{2}-\right.$ $\left.\mathrm{CH}_{2}-\mathrm{CH}_{3}\right){ }^{13} \mathrm{C}-\mathrm{NMR}\left(400 \mathrm{MHz}, \mathrm{CDCl}_{3}\right) \delta: 190 \cdot 4$ (carbonyl), 153.9, 149.5, 129.5, 126.4, 111.1, 108.9 (aromatic), 68.4, 55.6 (methoxy), 30.6, 18.8, 13.4 (aliphatic).

\subsection{Synthesis of N-hydroxyiminoacetyl acetone (4)}

A solution of acetyl acetone $(32.5 \mathrm{~mL}, 0.317 \mathrm{~mol})$ in $50 \mathrm{~mL}$ of glacial acetic acid was stirred at $5-10^{\circ} \mathrm{C}$ and then the cooled solution of sodium nitrite $(25 \mathrm{~g}$, $0.362 \mathrm{~mol})$ in water $(500 \mathrm{~mL})$ was added in portion wise over $30 \mathrm{~min}$ maintaining at the same temperature. After completion of addition, solution was slowly allowed to come up room temperature and additionally stirred for $5 \mathrm{~h}$. The reaction mixture extracted with diethyl ether, washed with $10 \%$ sodium bicarbonate solution $(3 \times 150 \mathrm{~mL})$ to remove unreacted acetic acid and dried over anhydrous sodium sulphate. The solvent was removed under vacuum to afford white powder of compound 4 (19.8 g, 48\%) FT-IR $\left(\mathrm{KBr}, \mathrm{cm}^{-1}\right): 3282(\mathrm{C}=\mathrm{N}), 3065(-\mathrm{N}-\mathrm{OH})$, $1698(-\mathrm{C}=\mathrm{O}) .{ }^{1} \mathrm{H}-\mathrm{NMR}\left(400 \mathrm{MHz}, \mathrm{CDCl}_{3}\right) \delta: 2 \cdot 38$ $\left(s, 3 \mathrm{H}, \mathrm{CH}_{3}\right),{ }^{13} \mathrm{C}-\mathrm{NMR}\left(400 \mathrm{MHz}, \mathrm{CDCl}_{3}\right) \delta: 195 \cdot 8$, $156 \cdot 1,28$.

\subsection{Synthesis of 4-acetyl-5-methyl-2-phenyl (3-methoxy-4-butyloxy)oxazole (5)}

To a solution of 4-butyloxy-3-methoxybenzaldehyde $(33 \times 48 \mathrm{~g} 0 \cdot 161 \mathrm{~mol})$ in glacial acetic acid $(16 \mathrm{~mL})$ was added N-hydroxyiminoacetyl acetone (27.3 g, $0.21 \mathrm{~mol}$ ) by one portion at room temperature. The reaction mixture was cooled to $0-5^{\circ} \mathrm{C}$ and subjected to flow of hydrogen chloride gas for $4 \mathrm{~h}$ with maintaining the same temperature. After the completion of flow of hydrogen chloride, the reaction mixture was poured into a beaker containing diethyl ether $(500 \mathrm{~mL})$ and stirred for $1 \mathrm{~h}$ to remove unreacted starting materials. The settled product at the bottom of beaker was filtered, dried and recrystallized by acetone to afford N-oxide hydrochloride of compound 5. It was dissolved in glacial acetic acid $(50 \mathrm{~mL})$ and activated zinc dust $(20 \mathrm{~g})$ was added and stirred well. After stirring, the reaction mixture was poured into water $(500 \mathrm{~mL})$ to separate out the desired product and dried. The obtained product was recrystallized from methanol to afford compound $\mathbf{5}$ as light yellow coloured powder $(42 \mathrm{~g}, 69 \cdot 10 \%)$. FT-IR $\left(\mathrm{KBr}, \mathrm{cm}^{-1}\right)$ : FT-IR $\left(\mathrm{KBr}, \mathrm{cm}^{-1}\right)$ : 2942 and $2865\left(-\mathrm{CH}_{2}-\right), 1611$ and 1518 (aromatic $-\mathrm{C}-\mathrm{H}$ ), $1678(\mathrm{Ar}-\mathrm{C}=\mathrm{O}), 1294$ and $1264(\mathrm{C}-\mathrm{O}-\mathrm{C}) .{ }^{1} \mathrm{H}-\mathrm{NMR}$ $\left(400 \mathrm{MHz}, \mathrm{CDCl}_{3}\right) \delta:{ }^{1} \mathrm{H}-\mathrm{NMR}\left(400 \mathrm{MHz}, \mathrm{CDCl}_{3}\right)$ $\delta: 7.47(s, 1 \mathrm{H}, \mathrm{Ar}), 6.85-7.08(\mathrm{~m}, 2 \mathrm{H}, \mathrm{Ar}), 3.78(\mathrm{~s}$, $\left.3 \mathrm{H}, \mathrm{Ar}-\mathrm{O}-\mathrm{CH}_{3}\right), 3.86\left(t, 2 \mathrm{H}, \mathrm{Ar}-\mathrm{O}-\mathrm{CH}_{2}-\right), 2.70(s$, $\left.3 \mathrm{H},-\mathrm{CO}-\mathrm{CH}_{3}\right), 2.48\left(\mathrm{~s}, 3 \mathrm{H},-\mathrm{CH}_{3}\right), 0.82-1.53(\mathrm{~m}$, $\left.7 \mathrm{H},-\mathrm{CH}_{2}-\mathrm{CH}_{2}-\mathrm{CH}_{3}\right) .{ }^{13} \mathrm{C}-\mathrm{NMR}\left(400 \mathrm{MHz}, \mathrm{CDCl}_{3}\right)$ $\delta$ : 201.09 (carbonyl), 156.3, 153.5, 150.5, 148.8, $135 \cdot 7,124 \cdot 3,119 \cdot 4,118 \cdot 8$ (aromatic), 68.8, 56.1 (methoxy), 28.1, 23.4, 12.3, 10.4, 9.8 (aliphatic).

\subsection{Synthesis of 5-methyl-2-phenyl(3-methoxy-4- butyloxy)oxazolylethylidene(isopropylidene) succinic acid (OFA)}

A solution of potassium-t-butoxide $(3.6 \mathrm{~g}, 0.032 \mathrm{~mol})$ in $40 \mathrm{~mL}$ of $t$-butanol under nitrogen was stirred at room temperature. To this, solution of compound 5 $(7.7 \mathrm{~g}, 0.0359 \mathrm{~mol})$ and compound $6(5.8 \mathrm{~g}, 0.019 \mathrm{~mol})$ in $t$-butanol $(40 \mathrm{~mL})$ were drop-wise added. After completion of addition, the reaction mixture was heated under reflux condition for $6 \mathrm{~h}$. Then, the mixture was cooled to room temperature; solvent concentrated under vacuum, poured into water $(200 \mathrm{~mL})$ and neutralized with $10 \% \mathrm{HCl}$ solution. The product was extracted with diethyl ether $(3 \times 150 \mathrm{~mL})$ and washed with $10 \%$ sodium bicarbonate solution $(3 \times 100 \mathrm{~mL})$ to remove pure half ester from organic layer. The combined bicarbonate solution was neutralized by $10 \% \mathrm{HCl}$ solution, extracted with diethyl ether again and dried over anhydrous sodium sulphate. The solvent was removed under vacuum to afford half acid, which was dissolved in ethanol $(100 \mathrm{~mL})$ and refluxed overnight with $\mathrm{KOH}(3 \mathrm{~g})$. After completion of reaction, solvent was concentrated under vacuum and poured into water $(200 \mathrm{~mL})$ and neutralized with $10 \% \mathrm{HCl}$ solution. The separated product was extracted with diethyl ether and dried over anhydrous sodium sulphate. The solvent was removed under vacuum to afford OFA as color- 
less powder, which was used in situ for succeeding step.

\subsection{Synthesis of 5-methyl-2-phenyl(3-methoxy-4- butyloxy)oxazolylethylidene(isopropylidene) succinic acid (OFO)}

The isopropenyl acetate $(6.6 \mathrm{~mL}, 60 \mathrm{mmol})$ was added into blended mixture of OFA $(2.2 \mathrm{~g}, 4.97 \mathrm{mmol})$ and montmorillonite KSF $(1 \mathrm{~g})$ in a flat-bottomed flask and stirred. It was irradiated under focused microwave $(2450 \mathrm{MHz})$ for $10 \mathrm{~min}$. After completion of reaction, mixture was cooled to room temperature and poured excess of chloroform and stirred. After 30 min of stirring, the clay was filtered off and chloroform removed under vacuum. The crude product was further purified by column chromatography to afford OFO as dark brown coloured powder $(1.52 \mathrm{~g}$, $72 \cdot 2 \%$,). M.p.: $145-149^{\circ} \mathrm{C}$. FT-IR $\left(\mathrm{KBr}, \mathrm{cm}^{-1}\right)$ : 2942 and $2865\left(-\mathrm{CH}_{2}-\right), 1834,1756(-\mathrm{C}=\mathrm{O}), 1610$ (oxazole $\mathrm{C}=\mathrm{N}$ ), 1294 and $1264(\mathrm{C}-\mathrm{O}-\mathrm{C}), 1041(\mathrm{Ar}-$ $\mathrm{C}=\mathrm{C}) .{ }^{1} \mathrm{H}-\mathrm{NMR}\left(400 \mathrm{MHz}, \mathrm{CDCl}_{3}\right) \delta: 7.83(s, 1 \mathrm{H}$, $\mathrm{Ar}), 7.42-7.53(\mathrm{~m}, 1 \mathrm{H}, \mathrm{Ar}), 6.96-7.03$ ( $m, 1 \mathrm{H}, \mathrm{Ar})$, $4.01\left(t, 2 \mathrm{H},-\mathrm{O}-\mathrm{CH}_{2}-\right), 3.78\left(s, 3 \mathrm{H}, \mathrm{Ar}-\mathrm{OCH}_{3}\right), 2.49$ $\left(s, 3 \mathrm{H}, \mathrm{CH}_{3}\right), 2.03\left(s, 3 \mathrm{H},-\mathrm{C}=\mathrm{C}\left(\mathrm{CH}_{3}\right)\right), 0.99-1.79$ ( $\left.m, 13 \mathrm{H},-\mathrm{CH}_{2}-\mathrm{CH}_{2}-\mathrm{CH}_{3}, \mathrm{CH}_{3}-\mathrm{C}-\mathrm{CH}_{3}\right) .{ }^{13} \mathrm{C}-\mathrm{NMR}$ $(400 \mathrm{MHz}, \mathrm{CDCl} 3) \quad \delta: 172.8,168.9$ (carbonyl), $163 \cdot 5,159 \cdot 8,152 \cdot 1,148 \cdot 4,146 \cdot 9,142 \cdot 3,123 \cdot 1$, $122 \cdot 7,121 \cdot 6,113 \cdot 3,112 \cdot 0,111 \cdot 8,67 \cdot 9,55 \cdot 5,48 \cdot 2$, $35 \cdot 2,35 \cdot 0,30 \cdot 6,22 \cdot 8,22 \cdot 7,20 \cdot 7,18 \cdot 7,13 \cdot 6$. Anal. Calcd. for $\mathrm{C}_{24} \mathrm{H}_{27} \mathrm{NO}_{6}: \mathrm{C}, 67.76 \%, \mathrm{H}, 6.35 \%, \mathrm{~N}$, $3.29 \%$ found $\mathrm{C}, 66 \cdot 48 \%, \mathrm{H}, 5 \cdot 82 \%, \mathrm{~N}, 2 \cdot 79$.

\section{Results and discussion}

The IFO and OFO were prepared from IFA and OFA in the presence of acetyl chloride and acetic anhydride in a relatively poor yield of $32 \%$ and $15 \%$ respectively. ${ }^{14,15}$ The IFA and OFA were prepared via Stobbe condensation of one mole of isopropylidenediethyl succinate and one mole of corresponding carbonyl compounds using sodium hydride and potassium tert-butoxide as base at room temperature respectively. The resultant products were hydrolysed using alcoholic $\mathrm{KOH}$ at reflux temperature for overnight. The poor yield of fulgides limits the large-scale utilization of fulgides for commercial and scientific investigations. To improve the yield of fulgides, IFO and OFO were prepared from corresponding fulgenic acid with varying proportions of Montmorillonite KSF and isopropenyl acetate (table 1) according to reported procedure for synthesis of anhydrides from corresponding dicarboxylic acids ${ }^{16}$ (schemes 1 and 2). To optimize the conditions for good yield, proportions of montmorillonite KSF and isopropenyl acetate were varied as shown in table 1 . Both IFO and OFO show maximum yield when $60 \mathrm{mmol}$ of isopropenyl acetate and $1 \mathrm{~g}$ of montmorillonite KSF proportions (table 1) employed respectively. It revealed that the proportions of clay and isopropenyl acetate play a key role in the yield of fulgides. Specifically in the presence of excess isopropenyl acetate, non-ionizing radiation increases the molecular motion of ions, rotation of dipoles in the reaction site of clay and increase the penetration depth of microwave radiation. ${ }^{16}$ Here, both IFO and OFO demonstrated good improvement in yield when compared with that of conventional chemical method used for synthesis of fulgides. The percentage yield of isomers of products was calculated from NMR spectral values of corresponding compounds. In the case of IFO, the E-isomer alone was formed (see supplementary informations) but in the case of OFO, Z-isomer was the major product. When compared to IFO, the OFO indicates less amount of yield with all concentration of isopropenyl acetate. The concentration of isopropenyl acetate is varied

Table 1. Improved yields of Fulgides IFO and OFO with different proportions of KSF and isopropenyl acetate.

\begin{tabular}{|c|c|c|c|c|c|c|c|c|c|}
\hline \multirow{2}{*}{$\begin{array}{l}\text { Fulgenic acid } \\
\text { derivative } \\
\text { IFA and OFA (mmol) }\end{array}$} & \multirow{2}{*}{$\begin{array}{l}\text { Isopropenyl } \\
\text { acetate } \\
\text { (mmol) }\end{array}$} & \multicolumn{4}{|c|}{ IFO (yield \%) } & \multicolumn{3}{|c|}{ OFO (yield \%) } & \multirow[b]{2}{*}{ Time (min) } \\
\hline & & $\mathrm{KSF}(\mathrm{g})$ & Net yield & E & $Z$ & Net yield & $E$ & $Z$ & \\
\hline 5 & 20 & 5 & 51 & 51 & 0 & 39 & 1 & 38 & 10 \\
\hline 5 & 30 & 4 & 60 & 60 & 0 & 44 & 2 & 42 & 10 \\
\hline 5 & 40 & 3 & 68 & 68 & 0 & $52 \cdot 7$ & $2 \cdot 4$ & $52 \cdot 3$ & 10 \\
\hline 5 & 50 & 2 & 76 & 76 & 0 & 65 & 1 & 64 & 10 \\
\hline 5 & 60 & 1 & 84 & 84 & 0 & $72 \cdot 2$ & $1 \cdot 2$ & 71 & 10 \\
\hline 5 & 60 & 0 & 20 & 20 & 0 & $10 \cdot 6$ & 0.7 & 9.8 & 10 \\
\hline
\end{tabular}


from 20 to $60 \mathrm{mM}$. Accordingly, the yield of $Z$ isomer increases proportionately with minor product of E-isomer (table 1). In the presence of $40 \mathrm{mM}$ of isopropenyl acetate and $3 \mathrm{~g}$ of $\mathrm{KSF}$ gives $54.7 \%$ yield with mixture of isomers. Methyl protons of $E$ isomer appeared at $2.46 \mathrm{ppm}$ as singlet with integral value of 0.07 and methyl protons of $Z$-isomer appeared at $2.41 \mathrm{ppm}$ as singlet with integral value of 1.64 in the ${ }^{1} \mathrm{H}-\mathrm{NMR}$ spectrum. Percentage yield of isomers was calculated using the integral values from the total yield (table 1). The ${ }^{1} \mathrm{H}-\mathrm{NMR}$ spectrum of IFO (see supplementary information, figure S1, see www.ias.ac.in) depicts four methyl groups resonated at four different positions between 1.24 and $3.67 \mathrm{ppm}$. The methylene proton resonated at $7.70 \mathrm{ppm}$ as singlet. The ${ }^{13} \mathrm{C}$-NMR spectrum (see supplementary information, figure S2) also shows four peaks in the aliphatic region corresponding to

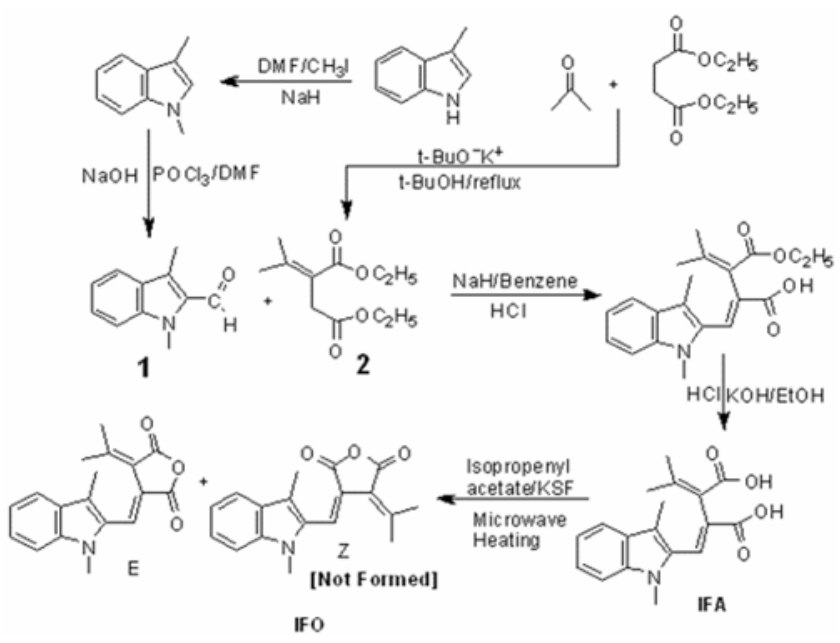

Scheme 1. Synthesis of IFA and IFO.

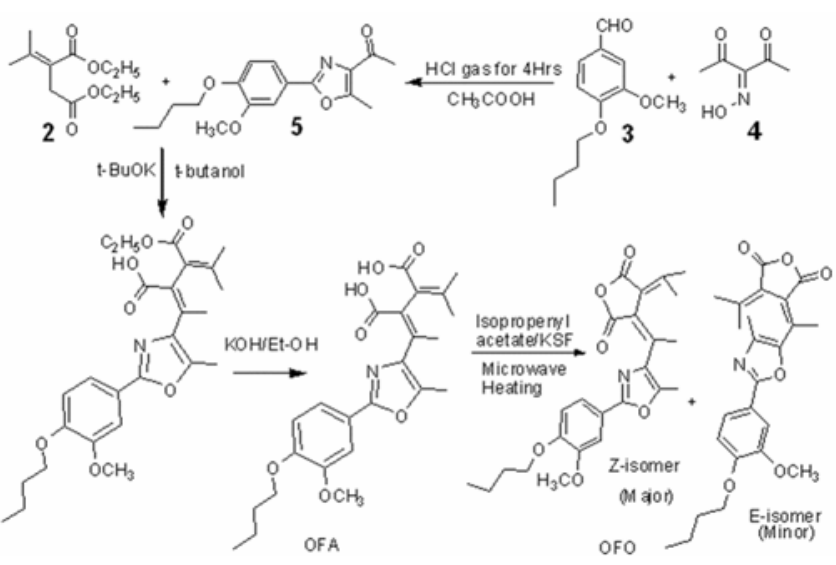

Scheme 2. Synthesis of OFA and OFO. four methyl carbon atoms. It indicated no characteristic peak for isomers in IFO. The chloroform solution of OFO was irradiated with $360 \mathrm{~nm}$ UV light for long time (30 $\mathrm{min})$; all the $Z$-form is isomerized to E-form. The methyleneoxy protons resonated as triplet at $4.00 \mathrm{ppm}$ and methoxy protons resonated as singlet at $3.78 \mathrm{ppm}$ in ${ }^{1} \mathrm{H}-\mathrm{NMR}$ spectrum of irradiated solution of OFO (see Supplementary information, figure S3). The oxazolyl methyl protons appeared at $2.49 \mathrm{ppm}$ as singlet. The ${ }^{13} \mathrm{C}$-NMR spec-

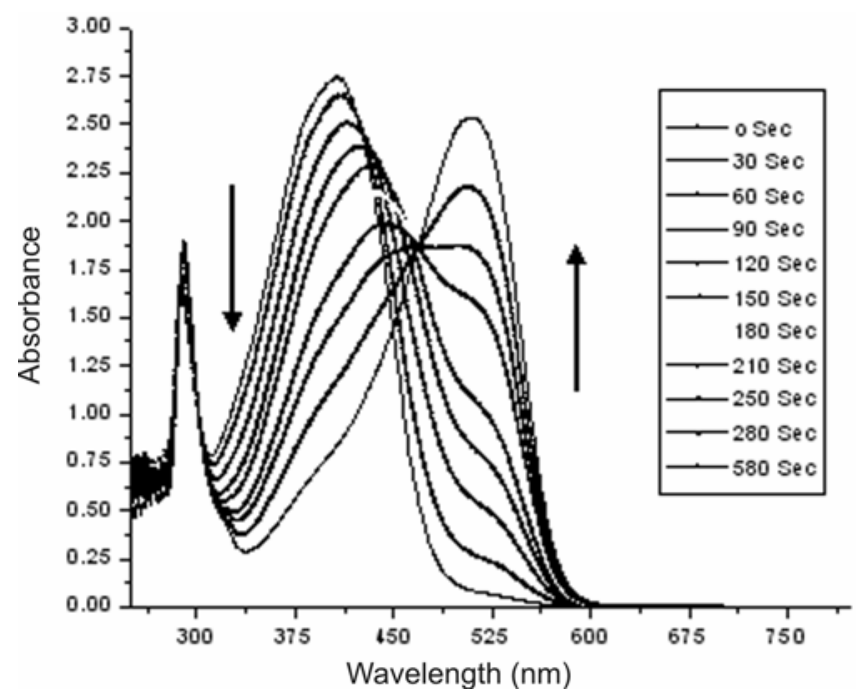

Figure 1. The absorption spectral pattern of IFO in chloroform solution upon irradiation $360 \mathrm{~nm}$ light.

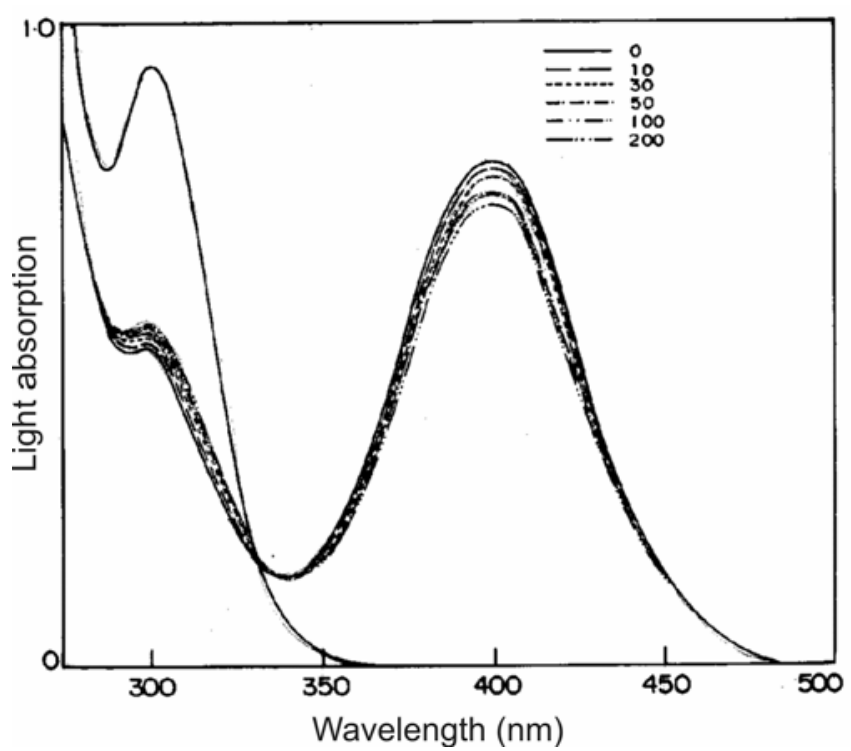

Figure 2. The absorption spectral pattern of OFO in chloroform solution upon irradiation with $360 \mathrm{~nm}$ light. 
trum (see Supplementary information, figure S4) also shows two peaks at 67.9 and $57.4 \mathrm{ppm}$ corresponding to methyleneoxy and methoxy protons respectively. After UV irradiation, the ${ }^{1} \mathrm{H}-\mathrm{NMR}$ spectrum of OFO confirms with no characteristic peaks for isomers (see Supplementary information, figure S3). The deviation in yield and $E$ and $Z$ isomeric ratios were around $2-3 \%$. The photochemical properties of fulgides were evaluated in chloroform solution. The absorption spectral changes of IFO and OFO in solution upon irradiation with $360 \mathrm{~nm}$ UV light are shown in figures 1 and 2 respectively. The solution of IFO shows an absorption band at $396 \mathrm{~nm}$ corresponding to E-form fulgide unit. Upon irradiation with $360 \mathrm{~nm}$ UV light, pale-orange colour solution of IFO turns blood red, with a new absorption band rising at $528 \mathrm{~nm}$ with a concomitant decrease in absorbance at $396 \mathrm{~nm}$ as shown in figure 1. In the case of OFO, E-form is converted to C-form and appeared at $452 \mathrm{~nm}$ upon irradiation with $360 \mathrm{~nm}$ UV light and the same solution was irradiated with $560 \mathrm{~nm}$ visible light, the intensity of absorption band at $362 \mathrm{~nm}$ increases with decrease at $452 \mathrm{~nm}$. These observations confirm the switching properties of IFO and OFO. ${ }^{14,15}$

\section{Supplementary material}

For all supplementary information see the website (www.ias.ac.in/chemsci).

\section{Conclusion}

The clay catalysed microwave-assisted strategy managed to synthesize fulgide of IFO and OFO successfully by simple and efficient means with improved yield over conventional methods. This methodology also brought down the reaction time and usage of organic solvents. This method found suitable for small-scale preparation and can be transformed to wide range of other fulgides.

\section{Acknowledgement}

The authors thank the Board of Research in Nuclear Sciences, Mumbai, Government of India (2006/37/ 13/BRNS/205) for financial support.

\section{References}

1. Bougrin K, Loupy A and Soufiaoui M 2005 J. Photochem. Photobiol. C: Photochem. Rev. 6139

2. Chaudhuri M K and Hussain S 2006 J. Chem. Sci. 118199

3. Yokoyama Y 2000 Chem. Rev. 1001717

4. Feringa B L 2004 Molecular switches (New York: Wiley-VCH) Chapter 4, p. 107

5. Yi C, Wang C, Fan M, Yao B and Menke N 2004 Opt. Mater. 2675

6. Belfield K D, Liu Y, Negres R A, Fan M, Pan G, Hagan D J and Hernandez F E 2002 Chem. Mater. 14 3663

7. Matsushima R, Nishiyama M and Doi M $2001 \mathrm{~J}$. Photochem. Photobiol A: Chem. 13963

8. Yi Chen, Jun P. Xiao, Yao B and Mei G 2006 Opt. Mater. 281068

9. Rybalkin V P, Shepelenko E N, Tkachev V V, Shilov G V, Balenko S K, Tsukanov A V, Popova L L, Dubonosov A D, Aldoshin S M, Bren V A and Minkina V I 2006 Russian Chem. Bull., Inter. Ed. 55101

10. Liang Y, Dvornikov A S and Rentzepis P M $2001 J$. Photochem. Photobiol. A: Chem. 83146

11. Thomas C J, Wolak M A, Birge R R and Lees W J 2001 J. Org. Chem. 661914

12. Lee W W, Gan L-M and Loh T-P 2007 J. Photochem. Photobiol. A: Chem. 185106

13. Perrin D D and Armarigo W L F 1998 Purification of laboratory chemicals (New York: Pergamon Press)

14. Liang Y C, Dvornikov A S and Rentzepis P M 1998 Res. Chem. Intermed. 24905

15. Tomoda A, Suzuki H, Kaneko A and Tsuboi H 1994 U S Patent No. 5,296,607

16. Villemin D, Labiad B and Loupy A 1993 Synth. Commun. 23419 